This is the peer reviewed version of the following article:

Battaglia, M., Touchette, É., Garon-Carrier, G., Dionne, G., Côté, S. M., Vitaro, F., Tremblay, R. E. \& Boivin, M. (2016) Distinct trajectories of separation anxiety in the preschool years: Persistence at school entry and early-life associated factors. Journal of Child Psychology and Psychiatry, 57(1), 39-46, which has been published in final form at : https://doi.org/10.1111/jcpp.12424.

This article may be used for non-commercial purposes in accordance with Wiley Terms and Conditions for Use of Self-Archived Versions.

5749 words (including the title page, abstract, text and references)

2 Tables and 1 Figure

\title{
Distinct trajectories of separation anxiety in the preschool years: persistence at school entry and early-life associated factors
}

\section{Short title: Evolution of separation anxiety symptoms in early childhood}

Marco Battaglia M.D. ${ }^{1,2}$, Évelyne Touchette, Ph.D. ${ }^{3,4}$, Gabrielle Garon-Carrier, B.A. ${ }^{4}$, Ginette Dionne, Ph.D. ${ }^{4}$, Sylvana M. Côté, Ph.D. ${ }^{5}$, Frank Vitaro, Ph.D. ${ }^{6}$, Richard E. Tremblay, Ph.D. ${ }^{5,7,8}$, \& Michel Boivin, Ph.D. ${ }^{4,7}$

${ }^{1}$ Department of Psychiatry and Neurosciences, Université Laval, Québec, Canada

${ }^{2}$ Centre de Recherche Institut Universitaire en Santé Mentale de Québec, Canada

${ }^{3}$ Département de psychoéducation, Université du Québec à Trois-Rivières, Québec, Canada

${ }^{4}$ GRIP, École de psychologie, Université Laval, Québec, Canada

${ }^{5}$ Department of Pediatrics and Psychology, Université de Montréal, Montréal, Canada

${ }^{6}$ Département de psychoéducation, Université de Montréal, Montréal, Canada.

${ }^{7}$ Institute of Genetic, Neurobiological, and Social Foundations of Child Development, Tomsk State University, Tomsk, Russian Federation

${ }^{8}$ School of Public Health, Physiotherapy and Population Sciences, University College Dublin, Dublin, Ireland

Disclosures and acknowledgements: All the authors report no conflicts of interest or financial disclosures. There was no off-label or investigational use. This was not an industry-supported study.

This study was funded by the Ministry of Health and Social Services (Quebec City, Quebec, Canada); the Canadian Institutes of Health Research (Ottawa, Ontario, Canada); the Social Sciences and Humanities Research Council of Canada (Ottawa, Ontario, Canada); the Quebec Fund for Research on Society and Culture (Quebec City, Quebec, Canada); the Quebec Fund for Research on Nature and Technology (Quebec City, Quebec, Canada); the Health Research Fund of Quebec (Quebec City, Quebec). We thank the children and families whose ongoing 
participation made this study possible. We acknowledge the considerable contribution of the coordinators of the Quebec Longitudinal Study of Child Development and the Quebec Institute of Statistics, and the tireless work of all the interviewers who assessed the mothers and children during the course of this study. We are thankful to Hélène Paradis for her valuable statistical expertise about separation anxiety trajectories. The authors report no conflicts of interest and financial disclosures. The first author had full access to all of the data in the study and takes responsibility for the integrity of the data and the accuracy.

Background: Little is known about how children differ in the onset and evolution of separation anxiety (SA) symptoms during the preschool years, and how SA develops into separation anxiety disorder. In a large, representative population-based sample, we investigated the developmental trajectories of SA symptoms from infancy to school entry, their early associated risk factors, and their associations with teachers' ratings of SA in kindergarten.

Methods: Longitudinal assessment of SA trajectories and risk factors in a cohort of 1933 families between the ages of 1.5 and 6 years.

Results: Analyses revealed a best-fitting, 4-trajectory solution, including a prevailing, unaffected Low-Persistent group (60.2\%), and 3 smaller groups of distinct developmental course: a HighIncreasing (6.9\%), a High-Decreasing (10.8\%) and a Low-Increasing group (22.1\%). The HighIncreasing group remained high throughout the preschool years and was the only trajectory linked to teacher-assessed SA in kindergarten. Except for the High-Increasing, all trajectories showed substantial reduction of symptom profile by age 6. The High-Increasing and HighDecreasing groups shared several early risk factors, but the former was uniquely associated with higher maternal depression, maternal smoking during pregnancy, and parental unemployment. Conclusions: Most children with high SA profile at age 1.5 years are expected to progressively recover by age 4-5. High SA at age 1.5 that persists over time deserves special attention, and may predict separation anxiety disorder. A host of child perinatal, parental, and family- 
contextual risk factors were associated with the onset and developmental course of SA across the preschool years.

Keywords: Separation anxiety, Trajectories, Risk factors, Internalizing disorders, Development

The diagnostic category of Separation Anxiety Disorder (SAD) is conceptually appealing, as it represents a dysfunctional exaggeration in duration and intensity of an otherwise adaptive, interspecific and evolution-derived mechanism, namely physiological separation anxiety (SA) (Ainsworth, Blehar, Waters, \& Wall, 1978). The earliest manifestation of SA probably coincided with the phylogenetic transition from reptiles to paleomammals (MacLean, 1985; Panksepp \& Biven, 2010), and coalesced with the behavioural and neuro-functional plasticity that underlies neomammals' evolutionary success. Today, parental nurturing and offspring-parent interactions would be difficult to conceive without the regulatory role of SA.

By recognizing SAD as an exaggerated and/or age-inappropriate manifestation in continuity with physiological SA, the DSM-V is consistent with prior diagnostic formulations (American Psychiatric Association, 2013). Exacerbations and remissions of anxiety about separation are commonly observed in children; accordingly, limited periods of heightened SA manifestations do not necessarily warrant a diagnosis of SAD (American Psychiatric Association, 2013), and may constitute transient and possibly adaptive responses to changing environments. Consistent with this notion, meta-analyses confirm that both family-wide and child-specific environmental factors affect SA and SAD throughout childhood over and above genetic influences (Scaini, Ogliari, Eley, Zavos, \& Battaglia, 2012).

It has recently become clear that $\mathrm{SAD}$ is far from rare and without consequences; with 4\% prevalence in population samples (Copeland, Angold, Shanahan, \& Costello, 2014) and 7.6\% 
in paediatric clinical samples (Ginsburg et al., 2014), childhood SAD has been identified as a possible gateway to both physical and psychiatric problems in adolescence and early adulthood (Battaglia et al., 1995; Copeland et al., 2014; Ginsburg et al., 2014; Klein, 1995; Kossowsky et al., 2013; Milrod et al., 2014; Shear, Jin, Ruscio, Walters, \& Kessler, 2006). However, since childhood anxiety disorders can be transient and often remit spontaneously (Ginsburg et al., 2014), it is paramount to identify factors that maintain elevated anxiety profiles over time, and predict a likely evolution toward clinical chronic disorders. These considerations are especially salient for SAD, due to its association with physiological SA. While large-scale epidemiological studies have reported age 6 years as the age of onset for typical SAD (Shear et al., 2006), recent paediatric primary care surveys indicate that SAD may be quite common among preschool children (Franz et al., 2013). However, very little is known about the early manifestations of SA and their bearing on the development of clinical SAD. Specifically, no study has described the longitudinal trajectories of SA in the general population, and documented whether any specific SA course of high intensity/stability predates full-blown SAD.

Moreover, we do not know which factors are associated with heightened or more persistent SA manifestations in early childhood. In previous longitudinal studies, family dysfunction (Côté et al., 2009; Ginsburg et al., 2014; Patton et al, 2014; Weeks et al., 2014), maternal depression, and child's externalized problems (Côté et al., 2009; Weeks et al., 2014) have been associated with early-onset and more severe course of internalized/anxious problems. However, there is a dearth of longitudinal information on SA specifically, let alone on the prenatal, perinatal, parental and social factors associated with the onset and developmental course of high SA in the preschool years.

Some reported associations between SAD, specific risk factors, and adult 
psychopathology appear counterintuitive. One conundrum relates to the role of real- vs. feared separation/loss in the aetiology of SA/SAD, and the later development of panic disorder (PD). In both clinical and community-based adult samples (Bandelow et al. 2001; Battaglia et al., 2009), a history of childhood SAD was found to predict PD in early adulthood (Kossowsky et al., 2013), and childhood parental loss has been associated with heightened risk for PD (Battaglia et al., 2009; Kessler, 2000). However, correlations between separation/loss events and retrospective assessments of childhood SAD were found close to zero (Bandelow et al., 2001; Battaglia et al., 2009). This suggests heterogeneous, or independent pathways from childhood adversities to the SAD-PD developmental continuum (Battaglia, Ogliari, D’Amato, \& Kinkead, 2014).

In this study of a large longitudinal birth cohort followed from age 1.5 years to age 6 years, we addressed 3 main questions, aimed at differentiating time-limited SA from the persistent and more pronounced SA manifestations that likely precede SAD. First, can we identify discrete patterns of temporal occurrence and strength of SA manifestations in the population? Second, what are the early life factors that are associated with differential stability and strength of SA manifestations? Third, which longitudinal preschool profile of parent-rated SA predicts teacher-rated SA manifestations at school entry?

\section{Methods}

\section{Setting}

This study was part of the Quebec Longitudinal Study of Child Development (QLSCD) (Petitclerc, Boivin, Dionne, Zoccolillo, \& Tremblay, 2009), which surveyed a representative sample of children born in 1997-98 in the province of Québec, Canada, except for children living in Cree or Inuit territories, Indian reserves, and northern Quebec. All children were recruited through the Quebec Master Birth Registry, by means of a stratified procedure based on living 
area and birth rate. Families were included if the pregnancy had lasted between 24 and 42 weeks, and the mother could speak French or English.

\section{Participants}

Initially, 2675 families were invited to participate in the study by mail and by telephone: $2223(83.1 \%)$ agreed to receive a first home visit when their index child was approximately 5 $(4.5 \pm 0.6)$ months old. All families had received detailed information by mail about the aims and procedures of the research program and signed a consent form. The protocol was approved by the Quebec Institute of Statistics.

Of the 2223 families met for a first visit, 2120 agreed to proceed and be re-assessed almost yearly until the age of 15 years; the first 4 assessments took place close to child's birthday, then during the spring of the following years. Here, we focus on a period spanning age 5 months to age 6 years $(73.8 \pm 3.1$ months, end of kindergarten $)$, the latter age representing the earliest age at onset for SAD indexed by large-scale epidemiological surveys (Shear et al., 2006). Moreover, Canadian children enter kindergarten at age 6 years, and thus begin to systematically experience separation from attachment figures several hours per day. The 5 months to age 6 years period thus involved 6 consecutive ratings according to the person most knowledgeable about the child (PMK, 99.7\% of times the mother), followed by one teacher rating of participants' SA in kindergarten.

A total of 1933 families (91.2\% of the 2120 final longitudinal sample) filled out the initial PMK ratings, and were then included in the present study. Compared to the 1933 participating families, the 187 families who dropped-out from the study were more likely to report lower income status $(\mathrm{p}<0.001)$, parental unemployment $(\mathrm{p}<0.001)$, mother not having completed a high school diploma $(\mathrm{p}=0.001)$ and having taken alcohol during pregnancy $(\mathrm{p}=0.001)$, divorce 
$(\mathrm{p}=0.001)$, child's co-sleep with parents/siblings ( $\mathrm{p}<0.001)$, and child's lower Apgar score 5 minutes after birth $(\mathrm{p}=0.008)$. Most of these same predictors have been associated with reduced participation in epidemiological studies (Kessler, 2000). Otherwise, the two sets of families did not differ on other measured socio-demographic, familial and individual characteristics (see Table 1 for a complete list).

\section{Measures}

Separation anxiety. SA was assessed at age 1.5, 2.5, 3.5, 4, 5 and 6 years through PMK's ratings $(0=$ never or rarely; $1=$ sometimes; $2=$ often $)$ of 3 items from the Child Behavior Checklist (Achenbach, 1991), which were asked by interviewers in a face-to-face structured interview: does your child: "react badly when a parent is away", "not want to sleep alone", "cling to adults and is too dependent"). The same 3 behavioural items were independently rated by kindergarten teachers at age 6 years. These three behaviours closely match the manifestations of SA (distress related to separation, reluctance to sleep separated from a major attachment figure, fear of being alone, or without an attachment figure) that best discriminate children with higher vs. lower SA according to item-response analyses (CooperVince, Emmert-Aronson, Pincus, \& Comer, 2014).

Principal component analyses of the SA items at each of the PMK's 6 assessment times systematically yielded a single factor solution accounting for $46.7 \%$ to $50.5 \%$ of variance, with items' loadings of comparable magnitude: 0.74 to 0.78 for "reacts badly when a parent is away", 0.70 to 0.77 for "clings to adults, too dependent", and 0.52 to 0.60 for "does not want to sleep alone". Cronbach alphas (mean $\alpha=.80$ ) were also consistently high across measurements. The SA factor scores derived from the single factor solution were used in the successive analyses to estimate SA trajectories. 
Perinatal and Early-Life Factors. At 5 months, the face-to-face interview with the PMK provided data on maternal education, child sex, age, birth weight (low $<2500 \mathrm{~g}$ ), prematurity (gestation $<37$ weeks), type of delivery, and apgar at 5 minutes after birth (as reported in the birth medical registry). Maternal smoking during pregnancy was coded present if the mother had smoked at least 1 cigarette/day while pregnant, and prenatal alcohol exposure was coded present if the mother endorsed having drunk alcohol at least once per week during pregnancy. Low economic status was determined through the combination of 3 indicators, family income, family size, and area of residence (ZIP code), according to Statistic Canada Low Income Cut-Offs (LICOs).

Postnatal Individual and Family-wide Factors. History of maternal postpartum depression was coded positive/negative at the 5 month interview; symptoms of current maternal depression were successively rated at the 17 month interview with the 12 -items version of the Center for Epidemiologic Studies Depression Scale (ESDS) (Poulin, Hand, \& Boudreay, 2005), by referring to the last week. Response categories ranged from 0 (none) to 3 (all the time), and the scores were then rescaled on a 10-point scale. Interviews at 5, 17 and 29 months also covered familial employment, parental separation, divorce, and death of $1^{\text {st }}$ degree relatives. Physical health problems were investigated by 2 variables: a) 'Child's diseases' (allergies, respiratory, cardiovascular, urologic, neurological conditions, as diagnosed by a health professional and lasting $\geq 6$ months), and b): 'Medical Admissions' (i.e., admissions to a health facility due to a medical/surgical condition). Externalized problems were assessed at 17 months and defined by a composite score ( $\alpha=.78)$ of hyperactivity (Galera et al. 2011) and physical aggression (Côté et al. 2007). Child's sleep problems: (a) <6 consecutive hours slept per night ( $<6$ hours), and b) cosleeping (i.e., sharing a room/bed with the parents/ siblings) were also assessed at 17 months 
(Touchette et al. 2005). The Parental Cognition and Conduct Toward the Infant Scale (Boivin et al. 2005) was administered to the PMK to monitor 4 dimensions of parenting: coercive parenting, overprotection, self-efficacy, and parental impact, according to a 0-10 point Likert scale.

\section{Procedure}

Pre-natal, perinatal, parental and social predictors of pre-school SA were collected at 5, 17, and 29 months of age with the PMK. At 6 years of age, from April to June, about 8 months after having entered kindergarten, teachers independently rated the same $3 \mathrm{SA}$ items that had been longitudinally rated by the PMK from age 1.5 to 6 years.

\section{Statistical analyses}

Specific trajectories based on the 6 longitudinal measures of SA provided by PMKs were first estimated through semi-parametric modeling (Nagin, 1999). Trajectory models allowing 2 to 5 trajectories of various shapes (intercept -0-, linear -1-, quadratic -2-, or cubic -3-) were compared using the PROC TRAJ SAS procedure (Jones, Nagin, \& Roeder, 2001). The maximum Bayesian information criterion (BIC) was first employed to determine the optimal number and shape of trajectories that best fitted the data, and then each individual was assigned to a specific SA trajectory based on the highest posterior probability of belonging to one specific trajectory.

The associations between SA trajectories and 25 explanatory variables -from perinatal to the 29 months' assessment- were first tested by Chi-square or ANOVA, as appropriate. A significance threshold at alpha $<0.002(0.05 / 25)$ was set after a conservative Bonferroni correction. Predictors that had resulted significantly associated with SA trajectories were then entered in a multivariate multinomial regression that tested their longitudinal association with the SA trajectories. Finally, one univariate general linear model (GLM) was run to estimate which 
PMK-informed trajectory could predict teacher-assessed SA at age 6 years. Aforementioned tests were estimated with the SPSS statistical software (SPSS Inc, Chicago, IL).

\section{Results}

\section{Trajectories of SA}

A four trajectory solution with a '2 231 ' profile (2 quadratic, 1 cubic and 1 linear trajectories) was identified as the best-fitting model (BIC=-13942.45). Figure 1 depicts the 4 trajectories that best fitted SA courses from age 1.5 to 6 years, according to the 6 serial assessments provided by the PMK. The most common trajectory (Low-Persistent, 60.2\%, $\mathrm{n}=1,163$ ) showed a pattern of low SA symptoms that remained constant throughout preschool. Two trajectories showed noticeable changes across time: one trajectory (High-Decreasing, $10.8 \%, \mathrm{n}=209$ ) was initially high on $\mathrm{SA}$, but decreased steadily over time to reach a level close to that of the Low-Persistent trajectory by age 5 years; the second evolving trajectory (LowIncreasing, 22.1\%, $\mathrm{n}=427$ ) had a curvilinear shape: it started low, then increased moderately until age 3.5, before abating to approximate the levels of the Low-Persistent and HighDecreasing SA by age 6 years. The fourth, and less common trajectory (High-Increasing, 6.9\%, $\mathrm{n}=134$ ) had a clear pattern of high, and steadily increasing SA scores. Due to its level, temporal pattern, and observed prevalence, this trajectory is the most likely to encompass children at risk for SAD.

Table 1 shows that most of the early life factors -at birth, at 17-, and at 29 months- were differently distributed across the 4 SA trajectories at $p<0.002$. The strongest differences across trajectories pertained to indices of familial hardship (unemployment, lower income, divorce), suboptimal parenting (low maternal impact perception and overprotection), maternal depression, low education, and smoking in pregnancy. Children of the High-Increasing and High- 
Decreasing SA trajectories had shorter sleep at night, and were more likely to co-sleep with parents and/or siblings. Of interest, hospitalization and illness, which can be traumatic and may imply separation from attachment figures, were not associated with any of the 4 SA trajectories.

Table 2 shows the results of the multivariate multinomial regression model, which tested longitudinal associations among risk factors and 3 trajectories of SA (High-Increasing, HighDecreasing, and Low-Increasing), compared to the Low-Persistent trajectory. The model included all covariates that were previously significantly found associated with the SA trajectories. This last regression model encompassed 1614 subjects. Low Apgar, maternal overprotection and low parental impact distinguished (albeit at varying levels of significance) all SA trajectories from the Low-Persistent trajectory. Parental unemployment, maternal depression and tobacco exposure in pregnancy were uniquely associated with the High-Increasing trajectory, while co-sleeping characterized both the High-Increasing and High-decreasing trajectories. Interestingly, parental divorce was not associated to either High-Increasing or High-Decreasing SA, and contributed only marginally to the Low-Increasing SA trajectory. Externalized problems were associated only to High-Decreasing and Low-Increasing SA.

Finally, a test of between-subjects effects yielded a significant prediction of teacherassessed SA by the PMK-based SA trajectories $(\mathrm{F}=6.61, \mathrm{DF}=3, \mathrm{p}<0.001)$; a post-hoc comparison of mean square differences showed that this was explained by the High-Increasing trajectory only (mean square $=-1.10,95 \%$ C.I $=-1.82$ to $-0.40, \mathrm{p}<0.05)$.

\section{Discussion}

This study was the first to document the developmental trajectories of SA from infancy to school entry, as well as their early associated factors in a large, representative population-based sample. Four distinct developmental trajectories of SA were revealed from age 1.5 to age 6 years. 
A Low-Persistent, unaffected group included the majority of children, and thus served as a contrast for the other three, less common, but distinctive developmental trajectories. These latter 3 trajectories differed in terms of onset and patterns of longitudinal expression of SA, as well as with respect to the early associated factors.

The High-Increasing was probably the most clinically relevant trajectory; with a symptom profile that was already prominent at age 1.5 years, and a steady incremental course throughout the preschool years, it was the only group membership that predicted teacherassessed SA in kindergarten. Such a high profile continuity from infancy to primary school is likely of predictive clinical significance. The proportion of children in our High-Increasing trajectory falls between the documented prevalence of SAD in population-based samples of older children (Copeland et al., 2014) and that found in paediatric clinical samples (Ginsburg et al., 2014). Longitudinal studies extending after age 6 will be needed to discriminate prospective 'SAD cases' from those High-Increasing SA children who do develop full-blown SAD. The present study differentiated the High-Increasing group from another, relatively common, high SA trajectory group, the High-Decreasing (10.8\%), on the basis of their longitudinal evolution. Like the High-Increasing, children in the High-Decreasing trajectory displayed high SA at age 1.5; however, they successively abated quickly, with 30\% symptom reduction already observable at age 2.5 , and over $60 \%$ reduction by age 3.5 . By age $5-6$, the High-Decreasing trajectory approximated the 'benchmark' Low-Persistent profile. The LowIncreasing SA profile (22.1\%) followed a similar fate by age 5-6 by displaying a curvilinear evolution over time.

A host of distinct, child, parent, and family-contextual risk factors discriminated among the different trajectories. The associations between these risk factors and the various SA 
trajectories were broadly consistent with reported links between family-wide factors and parentchild interactions among anxious/internalizing children (Côté et al., 2009; Ginsburg et al., 2014; Scaini et al., 2012; Weeks et al., 2014), On such account, it is paramount to distinguish the HighIncreasing and the High-Decreasing groups, as both trajectories showed high initial SA, but then took divergent developmental pathways. Both of these groups diverged from the normative LowPersistent by showing lower Apgar at birth, worse sleep quality indicators, and suboptimal parenting practices (lower parental impact and parental overprotection). However, the HighIncreasing group was uniquely characterized by higher maternal depression, unemployment, and maternal smoking during pregnancy. The higher maternal depression associated with the HighIncreasing profile could indicate increased familial-genetic risk underlying chronic SA and SAD (Weissman, 1990), and a relational context that reinforces SA over time (Herren, In-Albon, \& Schneider, 2013). The association with parental unemployment is consistent with previous longitudinal investigations of internalization/anxiety (Ginsburg et al., 2014; Weeks et al., 2014), and could reflect the interplay of intra-familial and extra-familial contexts (e.g., daycare) in accounting for a persistently high trajectory of preschool SA. Of the 2 perinatal indices initially associated with high SA -low Apgar scores and maternal smoking in pregnancy- only the latter distinguished the High-Increasing group from the Low-Increasing group. While associations with distal indices of physical health deserve deeper investigation, they are consonant with previous findings indicating that childhood SAD predicts physical health problems in early adulthood (Copeland et al., 2014), and further support a psychobiological connection between early adversities and SAD.

Our findings have implications for the early identification of children at risk for SAD and for preventive intervention. First, given its correlates and prevalence (6.9\%), the High-Increasing 
trajectory group most likely encompassed children with/at heightened risk for SAD. Children with high SA symptom profile at age 1.5 years who go on to exhibit high -or even increased- SA profiles at age 2.5 and 3.5, deserve attention as current or prospective possible cases of SAD. Second, an initially high level of SA symptoms does not necessarily evolve harmfully; in fact, the majority of the children $(60 \%)$ who displayed high SA at age 1.5 years had essentially recovered by age $4-5$. Thus, the early identification of children at risk for SAD should not rely solely on early assessment, but rather be based on a trajectory approach, i.e., repeated assessments over time.

Interestingly, higher externalization was specific of the High-Decreasing profile: while the nature of co-occurrence between internalized and externalized behaviour in childhood is a matter of debate (Cosgrove et al., 2011), this suggests that long-lasting SA is more likely to evolve as a 'mostly/purely internalizing' condition, and that pre-school children who are simultaneously high in SA and externalization are less likely to exhibit long-lasting high SA profiles. More generally, the developmental changes proper of early childhood often imply behavioural instability, and support symptom observation over longer periods than single-point sampling. This study of SA provides a clear test of this notion.

The inconsistence -or lack- of association between SA trajectories and several putative risk factors also provide valuable indications. Consistent with other studies of internalization before puberty (Kendall et al., 2010; Wang \& Zhao, 2014; Weeks, 2014), and with the notion that boys and girls do not significantly differ for SAD symptom presentation (American Psychiatric Association, 2013), there were no associations with sex for any of the 4 SA trajectories, Parental divorce was associated with SA trajectories, but only in the early (i.e., 1.52.5 years) window of measurement and in the univariate analyses (Table 1). This suggests that 
within the pre-school age window of risk, parental separation/divorce may only exert transitory effects on children's SA trajectories.

The present study should be interpreted in the context of 3 main limitations. First, the assessment of SA was reduced to only 3 key features. However, these features have been shown central to the construct and to the identification of children with marked SA and SAD (CooperVince et al., 2014). Second, this study did not assess familial risk for panic/agoraphobia, which could have further validated the differentiation among the 4 SA trajectories. However, the link between childhood SA and panic/agoraphobia has previously been shown in genetically informed studies (Battaglia et al., 2009) and confirmed by meta-analyses (Kossowsky et al., 2013). Third, our data and conclusions apply to a specific window of observation, covering age 1.5 years to 6 years. The same factors (e.g., parental separation/divorce) may show different associations with SA/SAD trajectories if applied to different ages and windows of risk. This notion is supported by longitudinal studies of adolescents into early adulthood (Patton et al., 2014), and by studies of gene-environment interaction (Nobile, Rusconi et al., 2009; Spatola et al., 2011), showing that the effect of a given risk factor may be detectable-alone or in interaction with other hazardous factors- only within specific windows of risk and development.

\section{Conclusion}

In harmony with developmental theory, our empirical data show that the vast majority of children experience little, or moderate time-limited separation anxiety form age 1.5 to 6 years. Children who display high levels of separation anxiety at age 1.5 and show a consistently increasing trend throughout age 4-5-6 years may constitute a specific population at risk for 
developing separation anxiety disorder. Maternal depression, maternal smoking during pregnancy, and unemployment further characterise this specific subpopulation.

\section{Correspondence}

Michel Boivin, PhD, École de Psychologie, Université Laval, Québec, QC, G1K 7P4, Canada $\underline{\text { michel.boivin@psy.ulaval.ca }}$ or: Marco Battaglia MD, Department of Psychiatry and Neurosciences, Université Laval, Québec, QC, Canada; marco.battaglia@fmed.ulaval.ca

- Little is known about the trajectories of separation anxiety, and which factors affect their intensity and persistence from early childhood to kindergarten.

- Longitudinal analyses of multiple parental ratings of separation anxiety items in a population cohort yielded 4 distinct trajectories, only one of which -the High-Increasing- showed consistently high and increasing symptoms from age 1.5 to age 6 years.

- The High-Increasing was the only trajectory linked to teacher-assessed separation anxiety in kindergarten, and was associated with higher rates of maternal depression, maternal smoking during pregnancy, and unemployment.

- Most children with high separation anxiety at age 1.5 years are expected to recover by age 45; however, high separation anxiety that persists over time deserves attention, and may predict separation anxiety disorder.

\section{Acknowledgements}

We thank the children and families whose ongoing participation made this study possible. We acknowledge the considerable contribution of the coordinators of the Quebec Longitudinal Study of Child Development and the Quebec Institute of Statistics, and the tireless work of all the interviewers who assessed the mothers and children during the course of this study. We are 
thankful to Hélène Paradis for her valuable statistical expertise about separation anxiety trajectories. The authors report no conflicts of interest and financial disclosures.

\section{References}

Achenbach, T.M. (1991). Child Behavior Checklist. Burlington: Department of Psychiatry, University of Vermont.

Ainsworth, M.S., Blehar, M.C, Waters, E., \& Wall, S. (1978). Patterns of attachment: A psychological study of the strange situation. Hillsdale: Erlbaum.

American Psychiatric Association (2013). Diagnostic and statistical manual of mental disorders. 5th ed. Arlington: American Psychiatric Publishing.

Bandelow, B., Alvarez Tichauer, G., Spath, C., Broocks, A., Hajak, G., Bleich, S., \& Ruther, E. (2001). Separation anxiety and actual separation experiences during childhood in patients with panic disorder. Canadian Journal of Psychiatry, 46, 948-952.

Battaglia, M., Bertella, S., Politi, E., Bernardeschi, L., Perna, G., Gabriele, A., \& Bellodi, L. (1995). Age at onset of panic disorder: influence of familial liability to the disease and of childhood separation anxiety disorder. American Journal of Psychiatry, 152, 1362-1364.

Battaglia, M., Ogliari, A., D’Amato, F.R., \& Kinkead, R. (2014, in press) Early-life risk factors for panic and separation anxiety disorder: insights and outstanding questions arising from human and animal studies of CO2 sensitivity. Neuroscience \& Biobehavioral Reviews.

Battaglia, M., Pesenti-Gritti, P., Medland, S.E., Ogliari, A., Tambs, K., \& Spatola, C.A. (2009). A genetically informed study of the association between childhood separation anxiety, 
sensitivity to $\mathrm{CO}(2)$, panic disorder, and the effect of childhood parental loss. Archives General Psychiatry, 66, 64-71.

Boivin, M., Pérusse, D., Dionne, G., Saysset, V., Zoccolillo, M., Tarabulsy, G., Tremblay, N., \& Tremblay, R.E. (2005). The genetic-environmental etiology of parents' perceptions and self-assessed behaviours toward their 5-month-old infants in a large twin and singleton sample. Journal of Child Psychology and Psychiatry, 46, 612-630.

Copeland, W.E., Angold, A., Shanahan, L., \& Costello, E.J. (2014). Longitudinal patterns of anxiety from childhood to adulthood: the Great Smoky Mountains Study. Journal of the American Academy of Child and Adolescent Psychiatry, 53, 21-33.

Cooper-Vince, C.E., Emmert-Aronson, B.O., Pincus, D.B., \& Comer, J.S. (2014). The diagnostic utility of separation anxiety disorder symptoms: an item response theory analysis. Journal of Abnormal Child Psychology, 42, 417-428.

Cosgrove, V.E., Rhee, S.H., Gelhorn, H.L., Boeldt, D., Corley, R.C., Ehringer, M.A., Young, S.E., \& Hewitt, J.K. (2011). Structure and etiology of co-occurring internalizing and externalizing disorders in adolescents. Journal of Abnormal Child Psychology, 39, 109123.

Côté, S.M., Boivin, M., Nagin, D.S., Janel, C., Xu, Q., Zoccolillo, M., Junger, M., \& Tremblay, R.E. (2007). The Role of Maternal Education and Nonmaternal Care Services in the Prevention of Children's Physical Aggression Problems. Archives General Psychiatry, 64, 1305-1312. 
Côté, S.M., Boivin, M., Xuecheng, L., Nagin, D.S., Zoccolillo, M., \& Tremblay, R.E. (2009) Depression and anxiety symptoms: onset, developmental course and risk factors during early childhood. Journal of Child Psychology and Psychiatry, 10, 1201-1208.

Franz, L., Angold, A., Copeland, W., Costello, E.J., Towe-Goodman, N., \& Egger, H. (2013). Preschool anxiety disorders in pediatric primary care: prevalence and comorbidity. Journal of the American Academy of Child and Adolescent Psychiatry, 52, 1294-1303.

Galera, C., Côté, S.M., Bouvard, M.P., Pingault, J-B., Melchior, M., Michel, G., Boivin, M., \& Tremblay, R.E. (2011). Early risk factors for hyperactivity-impulsivity and inattention trajectories from age 17 months to 8 years. Archives General Psychiatry, 68, 1267-1275.

Ginsburg, G.S., Becker, E.M., Keeton, C.P., Sakolsky, D., Piacentini, J., Albano, A.M., Compton, S.N., Iyengar, S., Sullivan, K., Caporino, N., Peris, T., Birmaher, B., Rynn, M., March, J., Kendall, P.C. (2014). Naturalistic follow-up of youths treated for pediatric anxiety disorders. JAMA Psychiatry, 71, 310-318.

Herren, C., In-Albon, T., \& Schneider, S. (2013). Beliefs regarding child anxiety and parenting competence in parents of children with separation anxiety disorder. Journal of Behavior Therapy and Experimental Psychiatry, 44, 53-60.

Jones, B.L., Nagin, D.S., \& Roeder, K. (2001). A SAS procedure based on mixture models for estimating developmental trajectories. Sociological Methods \& Research, 29, 374-393.

Kendall, P.C., Compton, S.N., Walkup, J.T., Birmaher, B., Albano, A.M., Sherrill, J., Ginsburg, 
G., Rynn, M., McCracken, J., Gosch, E., Keeton, C., Bergman, L., Sakolsky, D., Suveg, C., Iyengar, S., March, J., \& Piacentini, J. (2010). Clinical characteristics of anxiety disordered youth. Journal of Anxiety Disorders, 24, 360-365.

Kessler, R.C. (2000). Psychiatric epidemiology: selected recent advances and future directions. Bulletin of the World Health Organization, 78, 464-474.

Klein, RG. (1995). Is panic disorder associated with childhood separation anxiety disorder? Clinical Neuropharmacology, 18 (Suppl 2), S7-S14.

Kossowsky, J., Pfaltz, M.C., Schneider, S., Taeymans, J., Locher, C., \& Gaab, J. (2013). The separation anxiety hypothesis of panic disorder revisited: a meta-analysis. American Journal of Psychiatry, 170, 768-781.

MacLean, P.D. (1985). Brain evolution relating to family, play, and the separation call. Archives General Psychiatry, 42, 405-417.

Milrod, B., Markowitz, J.C., Gerber, A.J., Cyranowski, J., Altemus, M., Shapiro, T., Hofer, M., \& Glatt, C. (2014). Childhood separation anxiety and the pathogenesis and treatment of adult anxiety. American Journal of Psychiatry, 171, 34-43.

Nagin, D.S. (1999). Analyzing developmental trajectories: A semiparametric, group-based approach. Psychological Methods, 4, 139-157.

Nobile, M., Rusconi, M., Bellina, M., Marino, C., Giorda, R., Carlett, O., Vanzin, L., Molteni, M., \& Battaglia, M. (2009). The influence of family structure, the TPH2 G-703T and the 5-HTTLPR serotonergic polymorphisms upon preadolescents' affective problems. Journal of Child Psychology and Psychiatry, 50, 317-325.

Panksepp, J., \& Biven, L. (2010). The archaeology of mind: Neuroevolutionary origins of human emotion. New York: Norton WW Company. 
Patton, G.C., Coffey, C., Romaniuk, H., Mackinnon, A., Carlin, J.B., Degenhardt, L., Olsson, C.A., Moran, P. (2014). The prognosis of common mental disorders in adolescents: a 14year prospective cohort study. Lancet, 383, 1404-1411.

Petitclerc, A., Boivin, M., Dionne, G., Zoccolillo, M., \& Tremblay, R.E. (2009). Disregard for rules: the early development and predictors of a specific dimension of disruptive behavior disorders. Journal of Child Psychology and Psychiatry, 50, 1477-1484.

Poulin, C., Hand, D., \& Boudreay, B. (2005). Validity of a 12-item version of the CES-D used in the National Longitudinal Study of Children and Youth. Chronic Diseases and Injuries in Canada, 23, 65-72.

Scaini, S., Ogliari, A., Eley, T.C., Zavos, H.M., \& Battaglia, M. (2012). Genetic and environmental contributions to separation anxiety: a meta-analytic approach to twin data. Depression and Anxiety, 29, 754-761.

Shear, K., Jin, R., Ruscio, A.M., Walters, E.E., \& Kessler, R.C. (2006). Prevalence and correlates of estimated DSM-IV child and adult separation anxiety disorder in the national comorbidity survey replication. American Journal of Psychiatry, 163, 1074-1083.

Spatola, C.A.M., Scaini, S., Pesenti-Gritti, P., Medland, S.E., Moruzzi, S., Ogliari, A., Tambs, K., \& Battaglia, M. (2011) Gene-environment interactions in panic disorder and CO2 sensitivity: effects of events occurring early in life. American Journal of Medical Genetics Part B: Neuropsychiatric Genetics, 156, 79-88.

SPSS Inc. (2011). SPSS Base 16.0 for Windows User's Guide. SPSS Inc : Chicago, IL. Touchette, E., Petit, D., Paquet, J., Boivin, M., Japel, C., Tremblay, R.E., Montplaisir, J.Y. (2005). Factors associated with fragmented sleep at night across early childhood. Archives of Pediatrics and Adolescent Medicine, 159, 242-249. 
Wang, M., \& Zhao, J. (2014). Anxiety disorder symptoms in chinese preschool children. Child Psychiatry \& Human Development. [Epub ahead of print].

Weeks, M., Cairney, J., Wild, T.C., Ploubidis, G.B., Naicker, K., \& Colman, I. (2014). Early-life predictors of internalizing symptom trajectories in Canadian children. Depression and Anxiety, 31, 608-616.

Weissman, M.M. (1990). Evidence for comorbidity of anxiety and depression: Family and genetic studies of children, in Comorbidity of mood and anxiety disorders. Edited by Maser JD, Cloninger CR. Arlington: American Psychiatric Association, pp 349-365. 


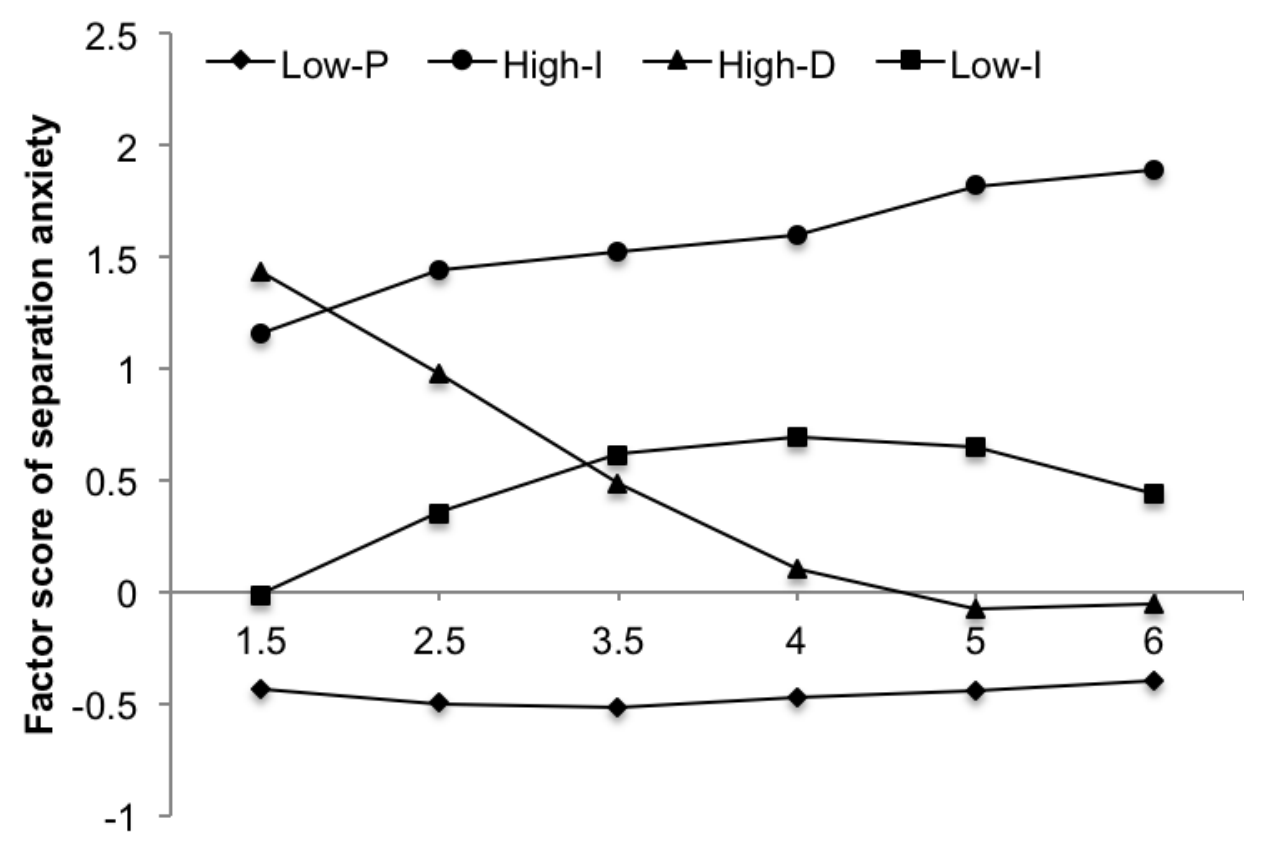

Figure 1. Patterns of separation anxiety at 1.5, 2.5, 3.5, 4, 5 and 6 years of age:

- High-Increasing separation anxiety trajectory $(\mathrm{n}=134 ; 6.9 \%), \boldsymbol{A}$-High-

Decreasing separation anxiety trajectory $(\mathrm{n}=209 ; 10.8 \%), \quad$ - Low-Increasing separation anxiety trajectory $(\mathrm{n}=427 ; 22.1 \%)$, and - - Low-Persistent separation anxiety trajectory $(\mathrm{n}=1163 ; 60.2 \%)$. Data courtesy of the Quebec Institute of Statistics. 
Table 1. Child characteristics, maternal characteristics and family-wide factors associated with trajectories of separation anxiety from birth to 29 months of age $(n=1933)$

\begin{tabular}{|c|c|c|c|c|c|c|}
\hline \multirow[b]{2}{*}{ Child, maternal and familial factors } & \multirow[b]{2}{*}{$\begin{array}{l}\text { Missing } \\
(\mathrm{n}=1933)\end{array}$} & \multicolumn{4}{|c|}{ Trajectories of separation anxiety } & \multirow[b]{2}{*}{$P$} \\
\hline & & $\begin{array}{l}\text { High- }\left.\right|^{a} \\
(n=134)\end{array}$ & $\begin{array}{l}\text { High-D } \\
(n=209)\end{array}$ & $\begin{array}{l}\text { Low-l } \\
(n=427)\end{array}$ & $\begin{array}{c}\text { Low-P } \mathbf{P}^{\mathbf{d}} \\
(n=1163)\end{array}$ & \\
\hline Child characteristics & & $n(\%)$ & $n(\%)$ & $n(\%)$ & $\mathrm{n}(\%)$ & \\
\hline \multicolumn{7}{|l|}{ At birth } \\
\hline Sex (girls) & $0(0.0)$ & $70(52.2)$ & $96(45.9)$ & $223(52.2)$ & $578(49.7)$ & .47 \\
\hline Low birth weight $(<2500 \mathrm{~g})$ & $11(0.0)$ & $4(3.0)$ & $5(2.4)$ & $21(5.0)$ & $36(3.1)$ & .26 \\
\hline Prematurity ( $<37$ weeks) & $0(0.0)$ & $7(5.2)$ & $9(4.3)$ & $32(7.5)$ & $45(3.9)$ & .03 \\
\hline Type of delivery (caesarean) & $18(0.0)$ & $21(16.4)$ & $22(10.6)$ & $83(19.5)$ & $169(14.7)$ & .02 \\
\hline Apgar (at 5 min) $\dagger$ & $32(0.0)$ & $9.2 \pm 1.0$ & $9.3 \pm 1.0$ & $9.3 \pm 0.9$ & $9.4 \pm 0.7$ & $<.001$ \\
\hline \multicolumn{7}{|l|}{ At 17 months } \\
\hline Child age (months) $\dagger$ & $8(0.0)$ & $17.1 \pm 0.5$ & $17.0 \pm 0.5$ & $17.1 \pm 0.5$ & $17.0 \pm 0.5$ & .18 \\
\hline Externalized problems $\dagger$ & $18(0.0)$ & $2.8 \pm 1.9$ & $2.8 \pm 1.8$ & $2.6 \pm 1.7$ & $2.2 \pm 1.6$ & $<.001$ \\
\hline Nighttime sleep ( $<6$ consecutive hours) & $119(0.1)$ & $18(14.6)$ & $25(13.1)$ & $29(7.2)$ & $50(4.5)$ & $<.001$ \\
\hline Sleep (parents' bedroom or siblings') & $90(0.0)$ & $63(49.2)$ & $89(44.7)$ & $104(25.9)$ & $220(19.7)$ & $<.001$ \\
\hline Child diseases & $9(0.0)$ & $15(11.3)$ & $17(8.2)$ & $42(9.9)$ & $109(9.4)$ & .80 \\
\hline Child medical admissions (at least one) & $8(0.0)$ & $23(17.3)$ & $26(12.5)$ & $45(10.6)$ & $143(12.3)$ & .24 \\
\hline \multicolumn{7}{|l|}{ Maternal characteristics } \\
\hline \multicolumn{7}{|l|}{ During pregnancy } \\
\hline Maternal alcohol consumption & $10(0.0)$ & $37(28.0)$ & $73(35.3)$ & $149(35.1)$ & $448(38.6)$ & .08 \\
\hline Maternal postnatal depression & $3(0.0)$ & $44(33.3)$ & $68(32.7)$ & $148(34.7)$ & $328(28.2)$ & .06 \\
\hline Maternal smoking & $10(0.0)$ & $47(35.6)$ & $59(28.5)$ & $129(30.4)$ & $250(21.6)$ & $<.001$ \\
\hline \multicolumn{7}{|l|}{ At 17 months } \\
\hline Maternal age (years) $\dagger$ & $10(0.0)$ & $30.2 \pm 6.4$ & $29.1 \pm 5.6$ & $30.0 \pm 5.2$ & $30.7 \pm 4.9$ & $<.001$ \\
\hline Maternal education (no high school diploma) & $10(0.0)$ & $50(37.6)$ & $62(29.8)$ & $87(20.6)$ & $126(10.9)$ & $<.001$ \\
\hline Maternal depression $\dagger$ & $18(0.0)$ & $2.2 \pm 1.8$ & $1.5 \pm 1.4$ & $1.5 \pm 1.4$ & $1.1 \pm 1.2$ & $<.001$ \\
\hline Maternal impact perception $\dagger$ & $68(0.0)$ & $7.4 \pm 2.2$ & $8.0 \pm 2.1$ & $8.1 \pm 1.9$ & $8.7 \pm 1.6$ & $<.001$ \\
\hline Maternal overprotection $\dagger$ & $79(0.0)$ & $6.3 \pm 2.5$ & $5.7 \pm 2.3$ & $5.2 \pm 2.3$ & $4.2 \pm 2.2$ & $<.001$ \\
\hline Maternal efficacy† & $85(0.0)$ & $8.4 \pm 1.3$ & $8.3 \pm 1.4$ & $8.3 \pm 1.4$ & $8.4 \pm 1.2$ & .31 \\
\hline Maternal coercion† & $79(0.0)$ & $3.5 \pm 2.4$ & $3.4 \pm 2.5$ & $3.4 \pm 2.3$ & $3.3 \pm 2.4$ & .83 \\
\hline \multicolumn{7}{|l|}{ Familial-wide factors } \\
\hline \multicolumn{7}{|l|}{ At 17 months } \\
\hline Low socioeconomic status & $31(0.0)$ & $57(43.8)$ & $62(30.5)$ & $107(25.7)$ & $135(11.7)$ & $<.001$ \\
\hline Parental unemployment & $10(0.0)$ & $29(21.8)$ & $19(9.2)$ & $43(10.1)$ & $34(2.9)$ & $<.001$ \\
\hline \multicolumn{7}{|l|}{ At 29 months } \\
\hline Parental divorce & $137(0.1)$ & $17(14.5)$ & $22(11.7)$ & $51(13.1)$ & $76(6.8)$ & $<.001$ \\
\hline Death of a family member & $125(0.1)$ & $0(0.0)$ & $0(0.0)$ & $1(0.3)$ & $2(0.2)$ & .87 \\
\hline \multicolumn{7}{|c|}{$\begin{array}{l}\text { Chi-square tests were used for categorical variables }(n, \%) \\
\text { ANOVAs were used for continuous variablest (mean } \pm \text { SD) }\end{array}$} \\
\hline \multicolumn{7}{|c|}{ aHigh-l refers to a trajectory of High-Increasing separation anxiety } \\
\hline \multicolumn{7}{|c|}{${ }^{\mathrm{b}}$ High-D refers to a trajectory of High-Decreasing separation anxiety } \\
\hline \multicolumn{7}{|c|}{ 'Low-1 refers to a trajectory of Low-Increasing separation anxiety } \\
\hline${ }^{d}$ Low- $P$ refers to a trajectory of Low-Persistent separat & & & & & & \\
\hline
\end{tabular}


Table 2. Associations between significant covariates (from Table $1 P<.002$ ) and trajectories of separation anxiety $(n=1614)$

\begin{tabular}{|c|c|c|c|c|c|c|c|c|c|}
\hline \multirow{3}{*}{ Variables } & \multicolumn{9}{|c|}{ Trajectories of separation anxiety } \\
\hline & \multicolumn{3}{|c|}{ High- $\left.\right|^{a}(n=97)^{d}$} & \multicolumn{3}{|c|}{ High- $D^{b}(n=163)^{d}$} & \multicolumn{3}{|c|}{ Low- $^{\circ}(n=346)^{d}$} \\
\hline & $\mathrm{OR}$ & $95 \% \mathrm{Cl}$ & $P$ & OR & $95 \% \mathrm{Cl}$ & $P$ & OR & $95 \% \mathrm{Cl}$ & $P$ \\
\hline Maternal depression† & 1.35 & $(1.16-1.55)$ & $<.001$ & 1.05 & $(0.92-1.21)$ & .46 & 1.10 & $(1.00-1.22)$ & .07 \\
\hline Maternal overprotection $\dagger$ & 1.36 & $(1.22-1.51)$ & $\lessdot .001$ & 1.26 & $(1.17-1.37)$ & $<.001$ & 1.19 & $(1.13-1.26)$ & $<.001$ \\
\hline Maternal impact perception $\dagger$ & 0.78 & $(0.70-0.87)$ & $\lessdot .001$ & 0.90 & $(0.81-0.99)$ & .03 & 0.89 & $(0.83-0.96)$ & .002 \\
\hline Parental unemployment & 3.66 & $(1.47-9.10)$ & .005 & 0.55 & $(0.19-1.59)$ & .27 & 1.16 & $(0.53-2.54)$ & .71 \\
\hline Apgar, 5 min $\dagger$ & 0.69 & $(0.54-0.89)$ & .004 & 0.83 & $(0.70-0.97)$ & .02 & 0.83 & $(0.70-0.97)$ & .02 \\
\hline Sleep arrangement, parents' bedroom or siblings' & 1.84 & $(1.10-3.05)$ & .02 & 2.24 & $(1.53-3.28)$ & $<.001$ & 1.04 & $(0.76-1.42)$ & .83 \\
\hline loking during pregnancy & 1.68 & $(1.00-2.74)$ & $<.05$ & 1.01 & $(0.67-1.53)$ & .95 & 1.17 & $(0.87-1.58)$ & .30 \\
\hline Child nighttime sleep, $<6$ consecutive hours & 2.04 & $(0.90-4.62)$ & .09 & 3.05 & $(1.69-5.52)$ & $<.001$ & 1.86 & $(1.08-3.11)$ & .03 \\
\hline Maternal education, no high school diploma & 1.64 & $(0.93-2.90)$ & .09 & 1.78 & $(1.13-2$ & .01 & 1.15 & $(0.78-1.69)$ & .47 \\
\hline Low socioeconomic status & 1.50 & $(0.80-2.82)$ & .20 & 1.56 & $(0.96-2.55)$ & .08 & 1.60 & $(1.08-2.37)$ & .02 \\
\hline Child externalized problems $\dagger$ & 1.09 & $(0.95-1.25)$ & .22 & 1.17 & $(1.05-1.30)$ & .004 & 1.12 & $(1.03-1.21)$ & .006 \\
\hline Parental divorce & 1.29 & $(0.62-2.69)$ & .49 & 1.62 & $(0.89-2.97)$ & .12 & 1.66 & $(1.06-2.59)$ & .03 \\
\hline Maternal age & 1.00 & $(0.96-1.05)$ & .89 & .97 & $(0.93-1.01)$ & .09 & 0.99 & $(0.97-1.02)$ & .68 \\
\hline
\end{tabular}

OR: odds ratio, $95 \% \mathrm{Cl}$ : confidence intervals, and $\dagger$ : continuous variables

${ }^{a}$ High-I refers to a trajectory of High-Increasing separation anxiety

${ }^{b}$ High-D refers to a trajectory of High-Decreasing separation anxiety

'Low-I refers to a trajectory of Low-Increasing separation anxiety

${ }^{d}$ compared to the Low-Persistent separation anxiety trajectory

Data are courtesy of the Quebec Institute of Statistics 